\title{
Water sources as reservoirs of Vibrio cholerae 01 and non-01 strains in Bepanda, Douala (Cameroon): relationship between isolation and physico-chemical factors
}

\author{
Jane-Francis Tatah Kihla Akoachere ${ }^{1,2^{*}}$ and Christelle Kwedjeu Pulcherie Mbuntcha ${ }^{1}$
}

\begin{abstract}
Background: Cholera has been endemic in Douala since 1971. Most outbreaks start from Bepanda, an overcrowded neighbourhood with poor hygiene and sanitary conditions. We investigated water sources in Bepanda as reservoirs of Vibrio cholerae, the causative agent of cholera, determined its antibiotic susceptibility and some physico-chemical characteristics that could maintain the endemicity of this organism in Bepanda.
\end{abstract}

Methods: Three hundred and eighteen water samples collected from 45 wells, 8 taps and 1 stream from February to July 2009 were analyzed for $V$. cholerae using standard methods. Isolates were characterized morphologically, biochemically and serologically. The disc diffusion technique was employed to investigate antibiotic susceptibility. Differences in prevalence of organism between seasons were analysed. Correlation strength and direction of association between physico-chemical parameters and occurrence of $\mathrm{V}$. cholerae was analyzed using the Kendall tau_b non-parametric correlation. This was further confirmed with the forward-stepwise binary logistic regression.

Results: Eighty-seven (27.4\%) samples were positive for $V$. cholerae. Isolation was highest from wells. The organism was isolated in the rainy season and dry season but the frequency of isolation was significantly higher $\left(x^{2}=7.009, \mathrm{df}=1\right.$, $P=0.008)$ in the rainy season. Of the 96 confirmed $V$. cholerae isolates, 32 (33.3\%) belonged to serogroup $O 1$ and 64 (66.6\%) were serogroup non-O1/non-0139. Isolates from tap (municipal water) were non-O1/non-O139 strains. Salinity had a significant positive correlation with isolation in the dry season $(+0.267, \mathrm{P}=0.015)$ and rainy season $(+0.223, P=0.028)$. The forward-stepwise method of binary logistic regression indicated that as $\mathrm{pH}(\mathrm{Wald}=11.753$, $d f=1), P=0.001)$ increased, odds of isolation of $V$. cholerae also increased $(B=1.297, S . E=0.378, E \operatorname{Ex}(B)=3.657)$. All isolates were sensitive to ciprofloxacin and ofloxacin. Multi-drug resistance was predominant among the non-01/ non-O139 isolates.

Conclusion: V. cholerae was found in wells and stream in both seasons. Cholera will continue to be a health threat in Bepanda if intervention measures to prevent outbreak are not implemented. Continuous monitoring of water sources in this and other cholera high-risk areas in Cameroon is necessary, for a better preparedness and control of cholera.

Keywords: Cholera, Water contamination, Serogoup 01, Serogroup non-1/non-O139, Physico-chemical factors, Antibiotic susceptibility

\footnotetext{
* Correspondence: jakoachere@yahoo.com

'Department of Microbiology and Parasitology, Faculty of Science, University of Buea, Buea, Cameroon

2Laboratory for Emerging Infectious Diseases, Faculty of Science, University of Buea, Buea, Cameroon
}

\section{Biomed Central}

(c) 2014 Akoachere and Mbuntcha; licensee BioMed Central Ltd. This is an Open Access article distributed under the terms of the Creative Commons Attribution License (http://creativecommons.org/licenses/by/2.0), which permits unrestricted use, distribution, and reproduction in any medium, provided the original work is properly credited. The Creative Commons Public Domain Dedication waiver (http://creativecommons.org/publicdomain/zero/1.0/) applies to the data made available in this article, unless otherwise stated. 


\section{Background}

Vibrio cholerae is the causative agent of cholera, a diarrheal disease with epidemic or pandemic potential. This enteric disease is characterized by profuse watery diarrhea and vomiting, resulting in dehydration, electrolytes loss and eventually hypovolemic shock and renal failure. Without prompt medical attention, death can occur within hours [1] in 30 to $40 \%$ of cases. Cholera remains a public health concern particularly in developing countries with lack or inadequate supply of potable water, poor hygiene and rudimentary sanitary facilities. Transmission is mainly by consumption of contaminated food and water. Thus, good hygiene, appropriate sanitation and safe water are of prime importance in the fight against cholera.

Vibrio cholerae is classified into more than 200 serogroups based on the somatic $\mathrm{O}$ antigen. These are grouped into three major groups: Vibrio cholerae O1, Vibrio cholerae O139 and Vibrio cholerae non-O1/non-O139. Epidemic cholera is caused by Vibrio cholerae O1 and O139 strains. Strains of the non-O1/non-O139 serogroup have been associated with sporadic cases of diarrhea disease $[2,3]$. The epidemic potential of the organism is conferred by the production of a potent cholera toxin (CT) and an adhesion factor toxin-co-regulated pilus (TCP). However, $\operatorname{ct} x A B$ and $t c p$ genes which code for these major virulence determinants have also been identified in environmental strains of some non-O1/non-O139 Vibrio cholerae [4,5], and their presence have been attributed to serogroup conversion through gene transfer mechanisms such as natural transformation [6] and transduction [7]. Thus for an effective diarrheal disease prevention programme in cholera endemic localities, it is important to include the surveillance for non-O1/non-O139 strains in environmental samples.

$V$. cholerae is autochthonous to the aquatic environment explaining its detection in diverse aquatic environments (brackish water, marine and fresh water) and the occurrence of sporadic outbreaks of cholera in nonendemic localities has been associated with floods contaminating water sources or imported cases. It can survive in some aquatic environments for months to years, in association with zooplankton and other aquatic organisms [8]. Both laboratory and field studies $[9,10]$ have shown that its occurrence in the aquatic habitat is influenced by physicochemical characteristics. Under adverse environmental conditions, it has been shown to exist in a viable but non-culturable state which could revert to a transmissible state when climatic conditions become favourable, suggesting that in endemic regions, the aquatic environment may serve as a reservoir for this pathogen in the absence of an outbreak of cholera. Thus a deep understanding of these factors would facilitate disease prediction and implementation of timely measures for prevention of outbreaks.
Treatment of cholera involves prompt rehydration to replace lost fluids and electrolytes, and administration of antibiotics. Although rehydration prevents death, antibiotics administration has been very crucial in reducing the shedding of the pathogen, preventing disease spread, treating severely ill patients by reducing the volume of diarrhea, and consequently, reducing the duration of illness and hospitalization. Like for most enteric pathogens, there are reports of changing antibiotic susceptibility pattern of Vibrio cholerae isolated from cholera cases in endemic regions due to the emergence and spread of multidrug resistant strains [11]. Worrisome also, are reports of Vibrio cholerae strains form environmental sources bearing $\mathrm{R}$ plasmids transferable by intraspecific and intergeneric matings [12]. These findings show that the organism is capable of acquiring or spreading resistance factors and thus the aquatic environment could serve as a reservoir for drugresistant strains. Therefore in cholera endemic regions, surveillance of antibiotic susceptibility patterns of the organism must include isolates from aquatic sources to identify effective agents for treatment so as to avert the unpleasant consequences of treatment failure.

Cholera has been endemic in Douala, the economic capital of Cameroon since 1971 [13] when the on-going $7^{\text {th }}$ pandemic hit the African continent. Outbreaks have been occurring almost every two years and have often started in Bepanda [14], a slum area with poor hygiene and sanitary conditions. Thus, as inhabitants of Douala are constantly threatened by outbreaks of cholera, it is important to study the reservoirs (particularly during a period with no disease outbreak) and environmental factors maintaining the endemicity of Vibrio cholerae in this region. This study was aimed at isolating and characterizing $V$. cholerae strains from water sources in Bepanda, determining the susceptibility of isolates to antibiotics and evaluating some physico-chemical parameters that could be supporting the survival of the organism in this locality, so as to generate information that could be exploited for cholera prevention and management.

\section{Methods}

\section{Study area}

Douala being the economic capital of Cameroon and major seaport handles the country's major imports and exports and has the highest number of industries. These factors attract more people to the city resulting in rapid population growth and urbanization. The population of the city of Douala is estimated at over 3 million inhabitants. Douala's climate is of the tropical monsoon type, with warm and humid conditions. Rainfall occurs throughout the year, with August being the wettest month and December the driest month. Access to clean and safe water or basic sanitary facilities particularly in densely populated areas is poor $[13,15]$. In 
such areas, most people obtain water from unprotected shallow wells that are rarely disinfected [16]. The main consequence of the use of contaminated water has been the occurrence of several outbreaks of cholera [14,17].

Bepanda is one of the most densely populated neighbourhoods of Douala (Figure 1). Inhabitants of Bepanda have limited access to adequate drinking water sources and improved sanitation facilities, as well as insufficient living area. Dug-wells are the main source of water supply. The stream in this area is a major site of domestic waste disposal including leachates from nearby latrines. It also serves as a recreation site. Most cholera outbreaks have started in Bepanda [13,14] since 1971 when the disease arrived Cameroon. Following the 2005 epidemic, this neighbourhood has had its name informally extended with cholera tag: "Bepanda cholera", to show it is renowned for cholera outbreaks.

\section{Study design}

Water samples were collected from 3 sources (wells $[n=45]$, taps $[n=8]$, stream $[n=1])$ monthly from February to July 2009 and analyzed for $V$. cholerae using standard methods. Isolates were characterized morphologically, biochemically and serologically. Susceptibility of Vibrio cholerae $\mathrm{O} 1$ and non-O1/nonO139 to antibiotics was determined. The relationship between some environmental factors (temperature, $\mathrm{pH}$ and salinity) and the occurrence of Vibrio cholerae was studied.

\section{Sample collection}

Three hundred and eighteen (318) water samples were collected from selected wells and taps as described by Cheesbrough [18], using sterile plastic containers $(500 \mathrm{~mL})$. Briefly, a sterile wedge was tied with a rope (about $15 \mathrm{~m}$ long) to increase the weight of the container. The set up was introduced in the well and the wedge caused the

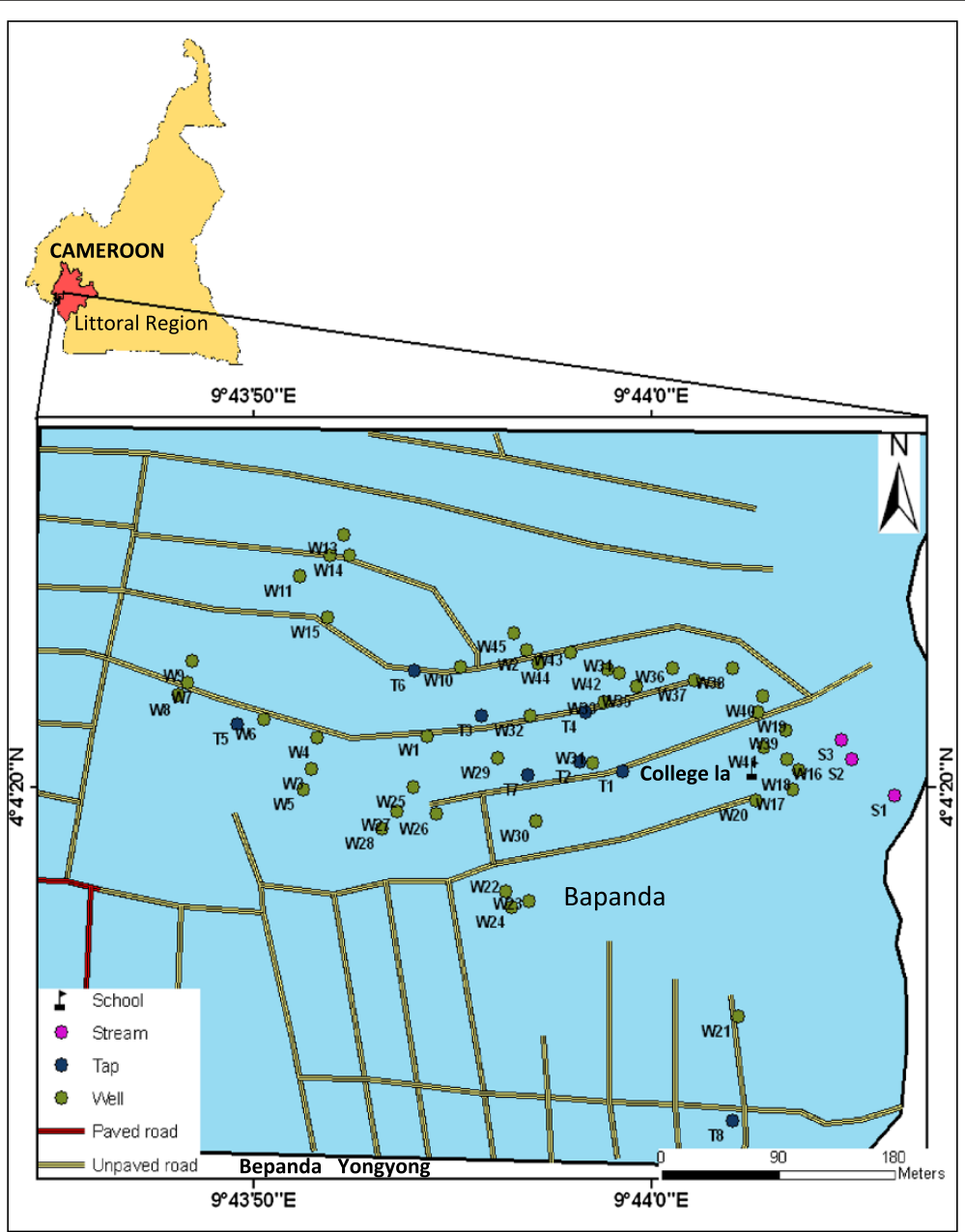

Figure 1 Map of the study area indicating sampling point (Source: Douala Urban Council). 
container to become submerged. The rope was pulled out of the well and the container corked and labelled. The same technique was used to collect samples from the stream at various locations (at least $200 \mathrm{~m}$ apart and $3 \mathrm{~m}$ away from the bank). Prior to collection from a tap, the tap opening was cleansed with $70 \%$ alcohol. The tap was opened and water allowed to flow for a few seconds, to flush out any contaminants. Water samples were packed in an insulated box and transported to the laboratory.

Samples were convenience samples. The coordinates of sites were obtained using a Global Positioning System (Guangzhou Making Electronic Technology Co., Ltd, China) as this information was not available prior to our study. During subsequent sampling visits, a GPS was used to locate the sampling points. Wells investigated were not protected [16]. Tap water in study area is part of a large drinking water treatment system which receives adequate disinfection.

\section{Isolation and identification of isolates}

Vibrio cholerae was isolated following enrichment in alkaline peptone water as described by Bag et al. [19] and Akoachere et al. [20]. Pure cultures were subjected to gram stain, motility, oxidase and catalase tests, and growth on Kliger Iron agar (KIA) slants. Their identity was confirmed using the Analytical Profile Index (API) 20E kits (BioMerieux SA, France). Isolates were serotyped using polyvalent Vibrio cholerae $\mathrm{O} 1$ and 139 antisera as described by CDC [21]. Isolates presenting a negative reaction with $V$. cholerae $\mathrm{O} 1$ polyvalent antiserum were typed using $V$. cholerae O139 polyavlent antiserum.

\section{Antibiotic Susceptibility Testing (AST)}

The disc diffusion (Kirby-Bauer) technique was employed to test the susceptibility of isolates to antibiotics as previously described by the National Committee for Clinical Laboratory Standards (presently called Clinical and Laboratory Standards Institute) [22]. Antibiotics tested included: tetracyclines [tetracycline $(30 \mu \mathrm{g})$, doxycycline $(30 \mu \mathrm{g})$ ], a $\beta$ lactam [amoxicillin $(30 \mu \mathrm{g})]$, $\beta$-lactmase inhibitor [augmentin $(30 \mu \mathrm{g})$ ], folic acid synthesis inhibitor [trimethoprimsulfamethoxazole (cotrimoxazole) $(25 \mu \mathrm{g})]$, fluoroquinolones [ciprofloxacin $(5 \mu \mathrm{g})$, ofloxacin $(5 \mu \mathrm{g})]$ and protein synthesis inhibitor [chloramphenicol $(30 \mu \mathrm{g})]$. These antibiotics have been used for treatment during previous outbreaks of cholera in Douala [23,24] or recommended for cholera treatment [25]. The diameters were compared with the recorded diameters of the control organism E. coli ATCC 25922 to determine susceptibility or resistance.

\section{Determination of physico-chemical characteristics of water samples}

Physico-chemical parameters (temperature, $\mathrm{pH}$ and salinity) were determined on site immediately after sample collection. A thermometer (Chemistry Thermometer, No 3200, Germany) was inserted into the sample and temperature reading recorded after 3 minutes. $\mathrm{pH}$ was measured using a $\mathrm{pH}$ meter (HANNA Instrument, HI 9811, UK). The electrode of the instrument was rinsed with the water sample of interest, and then inserted into the sample and value recorded when the meter stabilized. Salinity values were obtained by measuring conductivity of samples $(\mu \mathrm{S} / \mathrm{cm})$, using a conductivity meter (HANNA Instrument, HI 9811, UK). Conductivity values were then converted to salinity (ppm).

\section{Data analysis}

Statistical Package for Social Science (SPSS) version 15.0 was used to analyze data. The Chi-square $\left(X^{2}\right)$ test was employed to examine differences in the prevalence of $V$. cholerae in the water sources between seasons. The nonparametric analysis of variance (ANOVA) was used to describe and analyze variation in physico-chemical parameters. The Kendall $t a u_{-} b$ non-parametric correlation was employed to study the strength and direction of association between physico-chemical parameters and occurrence of $V$. cholerae. Binary logistic regression model (forward stepwise method) was used to estimate the coefficient of predictors (physico-chemical characteristics) in association with $V$. cholerae. Differences were considered significant at $\mathrm{P}<0.05$.

\section{Results}

\section{Contamination of water samples in the study area with Vibrio cholerae}

Eighty-seven (27.4\%) of the 318 samples analyzed were contaminated with $V$. cholerae. Stream samples (11/21, $52.4 \%$ ) were more frequently contaminated than samples from other sources (Table 1). There was a significant difference in isolation of the organism from samples from various sources $\left(\chi^{2}=8.830, \mathrm{df}=2, \mathrm{P}=0.012\right)$.

Among the 96 isolates characterized as $V$. cholerae, 32 (33.3\%) were Vibrio cholerae O1 while the rest 64 (66.7\%) belonged to the non-O1/non-O139 serogroup (Table 2). Vibrio cholerae $\mathrm{O} 1$ was isolated only from stream and well water samples. The majority of isolates from stream were $V$. cholerae $\mathrm{O} 1(9 / 14,64.3 \%)$. Isolates from tap water were serogroup non-O1/non-O139. Serogroup O139 was not

Table 1 Contamination of water sources with Vibrio cholerae

\begin{tabular}{lll}
\hline Source & $\begin{array}{l}\text { No. of samples } \\
\text { analyzed }\end{array}$ & $\begin{array}{l}\text { No. of samples } \\
\text { positive (\%) }\end{array}$ \\
\hline Well $(n=45)$ & 241 & $72(29.9)$ \\
Tap $(n=8)$ & 56 & $4(7.1)$ \\
Stream $(n=1)$ & 21 & $11(52.4)$ \\
Total & $\mathbf{3 1 8}$ & $\mathbf{8 7}(\mathbf{2 7 . 4 )}$ \\
\hline
\end{tabular}


Table 2 Isolation of $\boldsymbol{V}$. cholerae serogroups from water sources

\begin{tabular}{llll}
\hline Source & $\begin{array}{l}\text { No. of serogroup } \\
\text { O1 isolates } \\
\text { obtained }\end{array}$ & $\begin{array}{l}\text { No. of serogroup } \\
\text { non-O1/non-O139 } \\
\text { isolates (\%) }\end{array}$ & $\begin{array}{l}\text { Total no. of } \\
\text { V. cholerae } \\
\text { isolates (\%) }\end{array}$ \\
\hline Well & $23(29.5)$ & $55(70.5)$ & $78(81.3)$ \\
Tap & $0(0)$ & $4(100)$ & $4(4.2)$ \\
Stream & $9(64.3)$ & $5(35.5)$ & $14(14.6)$ \\
Total & $32(33.3)$ & $\mathbf{6 4}(66.7)$ & $96(100)$ \\
Statistics & $\begin{array}{l}X^{2}=16.237, \mathrm{df}=2 ; \\
\mathrm{P}=0.000\end{array}$ & $\begin{array}{l}X^{2}=2.706 ; \mathrm{df}=2 ; \\
\mathrm{P}=0.258\end{array}$ & $\begin{array}{l}x^{2}=8.830 ; \mathrm{df}=2 ; \\
\mathrm{P}=0.012\end{array}$ \\
\hline
\end{tabular}

isolated in our study. Among the 87 positive samples7 (8.1\%) had O1 serogroup, 59 (67.8\%) had non-O1 serogroup and $21(24.1 \%)$ were contaminated with both serogroups. Vibrio cholerae was detected in 35 wells, 3 taps and the stream investigated. Wells W12, W13, W14, W27 and W37 (Figure 1) had the highest number of isolates with $5,6,7,6$ and 5 isolates respectively obtained from these sources (Additional file 1). Serogroup O1 was detected in 20 wells. $V$. cholerae $\mathrm{O} 1$ and non-O1/non-O139 co-existed in $13(37.1 \%)$ wells and in the stream (Additional file 1).

\section{Seasonal distribution of $V$. cholerae in water sources}

$V$. cholerae $\mathrm{O} 1$ and non-O1/non-O139 were detected in both the dry and rainy seasons in wells. Both serogroups occurred in the stream only in the rainy season (Table 3, Additional file 2). Overall, the frequency of isolation of the organism was significantly higher $\left(\chi^{2}=7.009, \mathrm{df}=1\right.$, $\mathrm{P}=0.008)$ in the rainy season $(72 / 96,75 \%)$ than in the dry season $(24 / 96,25 \%)$. There was a significant difference in isolation of the serogroups between seasons.

\section{Physico-chemical characteristics of water samples and relationship with isolation of Vibrio cholerae}

Mean temperature of samples in the dry season was $29.08^{\circ} \mathrm{C}, 27.73^{\circ} \mathrm{C}$ and $28.1^{\circ} \mathrm{C}$ for stream, tap and well respectively (Table 4). Generally temperature values dropped

Table 3 Seasonal distribution of $\boldsymbol{V}$. cholerae isolates

\begin{tabular}{lllll}
\hline Season & $\begin{array}{l}\text { Sample } \\
\text { source }\end{array}$ & $\begin{array}{l}\text { No. of isolates } \\
\text { obtained (\%) }\end{array}$ & $\begin{array}{l}\text { Serogroup } \\
\text { O1 (\%) }\end{array}$ & $\begin{array}{l}\text { Serogroup non- } \\
\text { O1/non-O139 }\end{array}$ \\
\hline Dry season & Well & $20(20.8)$ & $5(5.2)$ & $15(15.6)$ \\
& Tap & $1(1)$ & $0(0)$ & $1(1)$ \\
& Stream & $3(3.1)$ & $3(3.1)$ & $0(0)$ \\
& Total & $\mathbf{2 4 ( 2 5 )}$ & $\mathbf{8}(\mathbf{8 . 3 )}$ & $\mathbf{1 6}(\mathbf{1 6 . 7 )}$ \\
Rainy season & Well & $58(60.4)$ & $18(18.8)$ & $40(41.7)$ \\
& Tap & $3(3.1)$ & $0(0)$ & $3(3.1)$ \\
& Stream & $11(11.5)$ & $6(6.3)$ & $5(5.2)$ \\
& Total & $\mathbf{7 2 ( 7 5 )}$ & $\mathbf{2 4 ( 2 5 )}$ & $\mathbf{4 8 ( 5 0 )}$
\end{tabular}

Overall isolation of $V$. cholerae: $\chi^{2}=7.009 ; \mathrm{df}=1 ; \mathrm{P}=0.008$.

$V$. cholerae $01: x^{2}=9.333, \mathrm{df}=1, \mathrm{P}=0.002$

V. cholerae non-01/non-0139: $X^{2}=3.889$, $\mathrm{df}=1, \mathrm{P}=0.049$. in the rainy season. Differences in temperature of samples from various sources were not significant $(\mathrm{F}=2.301, \mathrm{P}=$ 0.105). However, a significant difference was observed with season $(\mathrm{F}=471.5, \mathrm{P}<0.001)$. A significant positive correlation was observed between temperature and occurrence of Vibrio cholerae in the various water sources in the dry season $(+0.248, \mathrm{P}=0.030)$. Correlation was positive in the rainy season $(+0.012, \mathrm{P}=0.910)$ but weaker and not significant.

Mean values of $\mathrm{pH}$ recorded in the dry season were 6.87, 6.81 and 5.96 for the stream, tap and well samples respectively (Table 4). Highest and lowest $\mathrm{pH}$ values in both seasons occurred in well water. Variation in $\mathrm{pH}$ of samples between seasons was significant $(\mathrm{F}=68.8, \mathrm{P}<0.001)$. Significant differences were also observed in the $\mathrm{pH}$ of samples from different sources $(\mathrm{F}=8.224, \mathrm{P}<0.001)$. $\mathrm{pH}$ positively correlated with isolation of the organism in the dry season $(+0.184, \mathrm{P}=0.094)$ and in the rainy season $(+0.09$, $\mathrm{P}=0.379)$ but this was not significant.

Mean values of salinity recorded in the dry season were 4.4, 1.6 and 4.34 ppm for the stream, tap and well samples respectively (Table 4). Salinity had a similar trend to $\mathrm{pH}$ with the highest and lowest values in the two seasons occurring in well water samples. There was a significant difference between salinity values obtained in the dry season and rainy season $(\mathrm{F}=5.63, \mathrm{P}=0.019)$. Significant differences also occurred between samples from various sources $(\mathrm{F}=22.49, \mathrm{P}<0.001)$. A significant positive correlation between salinity and the isolation of $V$. cholerae was observed in the dry season $(+0.267, \mathrm{P}=0.015)$ as well as in the rainy season $(+0.223, \mathrm{P}=0.028)$.

In estimating the coefficient of physico-chemical characteristics of water samples and isolation of $V$. cholerae in a binary logistic regression using the forward-stepwise method with log likelihood function, it was observed that as $\mathrm{pH}$ (Wald $=11.753, \mathrm{df}=1$, $\mathrm{P}=0.001)$ increased, the odds of isolation of $V$. cholerae also increased $(B=1.297, S . E=0.378, \operatorname{Exp}(B)=$ 3.657) (Additional file 3). Salinity (score $=1.606, \mathrm{df}=1, \mathrm{P}$ $=0.205)$ and temperature (score $=0.050, \mathrm{df}=1, \mathrm{P}=0.824$ ) were insignificant to be included in the logistic regression equation (Additional file 3).

\section{Antibiotic susceptibility of $\boldsymbol{V}$. cholerae isolates}

All isolates (100\%) were sensitive to the fluoroquinolones: ciprofloxacin and ofloxacin (Table 5). Chloramphenicol, doxycycline and augmentin showed good activities. Generally, O1 isolates had higher susceptibilities than non-O1/non-O139 (Table 4). Lower susceptibilities were recorded for tetracycline $(62.5 \%$ and $50 \%$ for $\mathrm{O} 1$ and non-O1/non-O139 respectively), cotrimoxazole (65.6\% and $42.2 \%$ respectively for $\mathrm{O} 1$ and non-O1/non-O139 $V$. cholerae isolates) and ampicillin (64\% for non-O1/non-O139 serogroup). 
Table 4 Physico-chemical characteristics of water samples

\begin{tabular}{|c|c|c|c|c|c|c|c|c|c|}
\hline \multirow[t]{3}{*}{ Parameter } & \multirow[t]{3}{*}{ Season } & & \multicolumn{3}{|c|}{ Sample source } & \multicolumn{4}{|c|}{ One-way ANOVA of means } \\
\hline & & & \multirow[t]{2}{*}{ Stream } & \multirow[t]{2}{*}{ Tap } & \multirow[t]{2}{*}{ Well } & \multicolumn{2}{|c|}{ Sample source } & \multicolumn{2}{|c|}{ Season } \\
\hline & & & & & & $\bar{F}$ & $\mathbf{P}$ & $\bar{F}$ & $\mathbf{P}$ \\
\hline \multirow[t]{4}{*}{ Temperature $\left({ }^{\circ} \mathrm{C}\right)$} & Dry & Mean \pm SD & $29.08 \pm 0.63$ & $27.73 \pm 0.42$ & $28.15 \pm 0.45$ & 2.301 & 0.105 & 471.5 & $<0.001$ \\
\hline & & Range & $28.5-29.75$ & $27.33-28.5$ & 27.33-29.33 & & & & \\
\hline & Rainy & Mean \pm SD & $26.17 \pm 0.29$ & $25.79 \pm 0.21$ & $26.41 \pm 0.29$ & & & & \\
\hline & & Range & $26-26.5$ & $25.5-26$ & $25.67-27$ & & & & \\
\hline \multirow[t]{4}{*}{$\mathrm{pH}$} & Dry & Mean \pm SD & $6.87 \pm 0.3$ & $6.81 \pm 0.15$ & $5.96 \pm 0.65$ & 8.224 & $<0.001$ & 68.8 & $<0.001$ \\
\hline & & Range & $6.55-7.15$ & $6.6-7.03$ & $4.47-7.53$ & & & & \\
\hline & Rainy & Mean \pm SD & $7.58 \pm 0.28$ & $7.17 \pm 0.04$ & $6.91 \pm 0.35$ & & & & \\
\hline & & Range & 7.3-7.85 & 7.13-7.23 & $6.03-7.87$ & & & & \\
\hline \multirow[t]{4}{*}{ Salinity(ppm) } & Dry & Mean \pm SD & $4.4 \pm 0.45$ & $1.6 \pm 0.25$ & $4.34 \pm 2.23$ & 22.49 & $<0.001$ & 5.63 & 0.019 \\
\hline & & Range & $3.96-4.85$ & $1.47-2.22$ & $1.42-14.99$ & & & & \\
\hline & Rainy & Mean \pm SD & $6.27 \pm 0.57$ & $1.79 \pm 0.33$ & $5.31 \pm 1.43$ & & & & \\
\hline & & Range & $5.93-6.93$ & $1.54-2.43$ & $3.25-11.54$ & & & & \\
\hline
\end{tabular}

Kendall's tau b:

Dry season: temperature and isolation of $V$. cholerae: $+0.248, \mathrm{P}=0.030$.

$\mathrm{pH}$ and isolation of $\mathrm{V}$. cholerae: $+0.184, \mathrm{P}=0.094$.

Salinity and isolation of $V$. cholerae: $+0.267, P=0.015$.

Rainy season: temperature and isolation of $V$. cholerae: $+0.012, \mathrm{P}=0.910$.

$\mathrm{pH}$ and isolation of $\mathrm{V}$. cholerae: $+0.090, \mathrm{P}=0 . .379$.

Salinity and isolation of $V$. cholerae: $+0.223, P=0.028$.

Isolates showed multiple resistance (resistance to 2 or more drugs) to antibiotics. Four resistance patterns were observed among $V$. cholerae $\mathrm{O} 1$ isolates with patterns $\mathrm{TE}^{\mathrm{R}}$ $\mathrm{DXT}^{\mathrm{R}}(25 \%)$ and $\mathrm{AML}^{\mathrm{R}} \mathrm{TE}^{\mathrm{R}} \mathrm{SXT}^{\mathrm{R}}$ (58.3\%) being commonly encountered (Table 6). These patterns also predominated among the non-O1/non-O139 isolates. However, patterns $A M L^{R} S X T^{R} C^{R}$ and $A M L^{R} A U G^{R} C^{R}$ were found exclusively in Vibrio cholerae O1. Eleven (11) resistance patterns were unique to non-O1/non-O139 (Table 6).

\section{Discussion}

The city of Douala is well known as the main choleraendemic area of Cameroon. It has experienced more than ten outbreaks of cholera since the arrival of the

Table 5 Antibiotic susceptibility of $\boldsymbol{V}$. cholerae isolates

\begin{tabular}{llllll}
\hline Antibiotic & \multicolumn{2}{l}{ Number resistant (\%) } & & \multicolumn{2}{l}{ Number susceptible (\%) } \\
\cline { 2 - 3 } & $\begin{array}{l}\text { Serogroup } \\
\text { O1 }\end{array}$ & $\begin{array}{l}\text { Serogroup } \\
\text { non-01/ } \\
\text { non-0139 }\end{array}$ & $\begin{array}{l}\text { Serogroup } \\
\text { O1 }\end{array}$ & $\begin{array}{l}\text { Serogroup } \\
\text { non-O1/ } \\
\text { non-0139 }\end{array}$ \\
\hline Amoxicillin & $10(31.3)$ & $23(36)$ & $22(68.8)$ & $41(64)$ \\
Augmentin & $6(18.8)$ & $7(11)$ & $26(81.3)$ & $57(89)$ \\
Ofloxacin & $0(0)$ & $0(0)$ & $32(100)$ & $64(100)$ \\
Ciprofloxacin & $0(0)$ & $0(0)$ & $32(100)$ & $64(100)$ \\
Tetracycline & $12(37.5)$ & $32(50)$ & $20(62.5)$ & $32(50)$ \\
Doxycycline & $3(9.4)$ & $9(14.1)$ & $29(90.6)$ & $55(85.9)$ \\
Cotrimoxazole & $11(34.4)$ & $37(57.8)$ & $21(65.6)$ & $27(42.2)$ \\
Chloramphenicol & $2(6.3)$ & $2(3)$ & $30(93.8)$ & $62(97)$ \\
\hline
\end{tabular}

disease in Cameroon in 1971, most of which have originated from Bepanda [13,14]. We analyzed water from various sources in Bepanda during a period with no known disease outbreak for the presence of $V$. cholerae, studied its susceptibility pattern to drugs used in cholera management and also determined the physico-chemical parameters associated with the presence of the organism in water in the study locality.

Eighty-seven samples (27.4\%) were contaminated with Vibrio cholerae. $V$. cholerae is a normal inhabitant of natural aquatic environments such as rivers, estuaries and coastal waters [26] and has been detected in natural waters worldwide, including areas where clinical cases of cholera did not exist [27]. Samples from the stream were more contaminated. There was a significant difference in the prevalence of the organism in samples from various sources (Table 1). Most isolates were from wells. This is not surprising because recent reports [16] are showing deteriorating quality of water from dug-wells in study area. We could not access some wells and taps which were in premises with a gated fence since at times, there was no one within the premises to open the gate and let us in. The following wells were not sampled during the following months: March: $W_{13}, W_{16}, W_{25}$, $\mathrm{W}_{37}, \mathrm{~W}_{40}$; April: $\mathrm{W}_{1}, \mathrm{~W}_{3}, \mathrm{~W}_{9}, \mathrm{~W}_{18}, \mathrm{~W}_{21}, \mathrm{~W}_{45}$; May: $\mathrm{W}_{10}, \mathrm{~W}_{15}, \mathrm{~W}_{24}, \mathrm{~W}_{28}, \mathrm{~W}_{33}, \mathrm{~W}_{41}, \mathrm{~W}_{42}$; June: $\mathrm{W}_{12}, \mathrm{~W}_{7}$, $\mathrm{W}_{8}, \mathrm{~W}_{14}, \mathrm{~W}_{32}$; July: $\mathrm{W}_{11}, \mathrm{~W}_{22}, \mathrm{~W}_{30}, \mathrm{~W}_{39}, \mathrm{~W}_{43}, \mathrm{~W}_{44}$. Initially we had 6 sampling points on the stream. After the first visit, access way to three of those points was 
Table 6 Resistance patterns of $V$. cholerae isolates

\begin{tabular}{|c|c|c|}
\hline \multicolumn{3}{|c|}{ SEROGROUP 01} \\
\hline No. & Resistance pattern & $\begin{array}{l}\text { No. exhibiting resistance } \\
\text { pattern (\%) }\end{array}$ \\
\hline$R_{1}^{*}$ & $T^{T}{ }^{R} D_{X X}{ }^{R}$ & $3(25)$ \\
\hline$R_{2}^{*}$ & $A M L^{R} T^{R} S X T^{R}$ & $7(58.3)$ \\
\hline$R_{3}$ & $A M L{ }^{R} S X T^{R} C^{R}$ & $1(8.3)$ \\
\hline $\mathrm{R}_{4}$ & $A M L{ }^{R} A \cup G^{R} C^{R}$ & $1(8.3)$ \\
\hline Total & & $12(37.5)$ \\
\hline \multicolumn{3}{|c|}{ SEROGROUP NON-01/NON-0139 } \\
\hline No. & Resistance pattern & $\begin{array}{l}\text { No. exhibiting resistance } \\
\text { pattern (\%) }\end{array}$ \\
\hline$R_{5}$ & $A M L^{R} S X T^{R}$ & $4(11.8)$ \\
\hline$R_{6}$ & $A M L^{R} T^{R}$ & $1(2.9)$ \\
\hline $\mathrm{R}_{7}$ & $A \cup G^{R} T E^{R}$ & $1(2.9)$ \\
\hline$R_{8}$ & $A M L^{R} A \cup G^{R}$ & $1(2.9)$ \\
\hline$R_{9}^{*}$ & $T_{E}{ }^{R} D_{X} T^{R}$ & $4(11.8)$ \\
\hline $\mathrm{R}_{10}$ & $T^{R}{ }^{R} S X T^{R}$ & $4(11.8)$ \\
\hline$R_{11}$ & $T^{R}{ }^{R} D_{X T^{R}} S X T^{R}$ & $2(5.9)$ \\
\hline$R_{12}^{*}$ & $A M L^{R} T^{R}{ }^{R} S X T^{R}$ & $10(29.4)$ \\
\hline$R_{13}$ & $A M{ }^{R} A \cup G^{R} S X T^{R}$ & $1(2.9)$ \\
\hline $\mathrm{R}_{14}$ & $A \cup G^{R} T^{R} S X T^{R}$ & $2(5.9)$ \\
\hline$R_{15}$ & $A M L^{R} T^{R}{ }^{R} D X T^{R} S X T^{R}$ & $2(5.9)$ \\
\hline $\mathrm{R}_{16}$ & $A M L^{R} T^{R} S X T^{R} C^{R}$ & $1(2.9)$ \\
\hline$R_{17}$ & $A M L^{R} T^{R}{ }^{R} D X T^{R} S X T^{R} C^{R}$ & $1(2.9)$ \\
\hline Total & & $34(53.1)$ \\
\hline
\end{tabular}

AML, amoxicillin; AUG, augmentin; TE, tetracycline; DXT, doxycycline; SXT, trimethoprim/sulfamethoxazole; $C$, chloramphenicol; $R$, resistant; * resistance patterns detected in both Vibrio cholerae 01 and non-01/non-0139 strains.

blocked and we never sampled from there again. We also had more taps on the first visit but subsequently we were not able to sample from some of them.

Serological characterization of $V$. cholerae isolates identified $32(33.3 \%)$ and $64(66.7 \%)$ isolates belonging to serogroups $\mathrm{O} 1$ and non-O1/non-O139 respectively (Table 2). Both serogroups were isolated in the dry and rainy seasons (Table 3) indicating the presence of the organism all year round in study site. However, the majority of isolates were obtained during the rainy season. In Douala, the rainy season is characterized by torrential rains, which result in flooding and runoffs loaded with contaminants from diverse origins to water sources. The majority of the wells in Bepanda are poorly constructed and not well protected [16]. During periods of flood water may fill pit latrines and re-distribute faecal matter resulting in contamination of wells and surface water sources. Improvement of sanitation and access to safe water sources are urgently needed in Bepanda. In addition, continuous monitoring of water sources in study area is necessary for a better preparedness and control of cholera and cholera-like disease.
$V$. cholerae non-O1/non-O139 was isolated from all sources. Although non-O1/non-O139 strains do not cause epidemic cholera, they are recognized to be of public health relevance because they have been associated with sporadic cases or outbreaks of cholera-like diseases $[3,28]$ and many extra-intestinal infections $[2,29,30]$. The emergence of serogroup O139 as a second etiologic agent of cholera epidemics, along with the possible conversion of non-O1 to $\mathrm{O} 1$ serotype $[31,32]$ has increased interest in non-O1/nonO139 V. cholerae strains. Members of non-O1/non-O139 serogroup do not produce major virulence factors but genes coding for virulence factors have been identified in certain strains of both clinical and environmental origins $[4,5]$. Thus, non-O1/non-O139 serogroup in the study area may constitute a public health risk. Studies are underway in our laboratory investigating the virulence potential of non-O1/non-O139 Vibrio cholerae from the aquatic environment of parts of the city of Douala where devastating outbreaks of cholera had occurred to show their possible involvement in diarrheal disease in these areas. All isolates from tap water were serogroup nonO1/non-O139. Municipal water distributed in Douala undergoes adequate treatment prior to distribution. Contamination of tap water could have been through a leakage along the distribution mains which we observed during sample collection. Thus prompt repairs of leaking pipes his highly solicited to prevent recontamination of treated water.

Serogroup O139 was not detected in our study. Since the detection of this strain in 1992 as another cause of epidemic cholera [32], cholera caused by serogroup O139 had been limited to the Indian sub-continent and thus was believed to be of no public health importance in Africa. However, du Preez et al. [33] detected V. cholerae O139 strain in the estuarine environment of Mozambique indicating its spread out of the Indian sub-continent. These findings call for the inclusion of $V$. cholerae $\mathrm{O} 139$ in cholera surveillance in cholera endemic areas where this strain has never been reported.

Serogroup O1 was isolated only from wells and stream samples (Table 2). This is of great public health importance as toxigenic strains are responsible of cholera outbreaks and epidemics. Although we did not investigate the potential of our isolates to cause disease, their detection in waters is expected to serve as warning against an impending outbreak of cholera if appropriate preventive measures are not enforced. Inhabitants of the locality studied, therefore run the risk of experiencing cholera outbreak in the future, since most of them use well water for drinking, cooking and washing. There was no outbreak of cholera during the period of our study.

Environmental factors such as temperature, salinity, rainfall, sunlight, $\mathrm{pH}$, concentration of ferric ions, exogenous products of algal growth and chitin have been 
associated with $V$. cholerae dynamics [34]. A significant positive correlation was observed between temperature and occurrence of Vibrio cholerae in the various water sources in the dry season $(+0.248, \mathrm{P}=0.030)$ (Table 4). Correlation was positive in the rainy season $(+0.012, \mathrm{P}=$ 0.910 ) though weaker and not significant. $\mathrm{pH}$ positively correlated with isolation of the organism in the dry season $(+0.184)$ and rainy season $(+0.09)$ but correlation was not significant in both seasons $(\mathrm{P}=0.094$ and $\mathrm{P}=$ 0.379 for dry and rainy season respectively). Salinity had a significant positive correlation with the occurrence of the organism in the dry season $(+0.267, \mathrm{P}=0.015)$ as well as rainy season $(+0.223, \mathrm{P}=0.028)$ showing salinity to be strongly associated with $V$. cholerae isolation from water sources in Bepanda. However, salinity did not score significantly in the logistic regression model. Salinity has been demonstrated to influence significantly the growth of $V$. cholerae in cholera endemic areas [35,36]. We did not explore lagged relationships eventhough previous studies have shown significant associations. $\mathrm{pH}$ (Wald $=11.753, \mathrm{df}=1$, $\mathrm{P}=0.001$ ) was the only significant predictor from the binary logistic regression. Comprehensive studies would be necessary to evaluate the influence of $\mathrm{pH}$ on the presence of $V$. cholerae in the aquatic environment of Bepanda.

Isolates exhibited $100 \%$ susceptibility to fluoroquinolones: ciprofloxacin and ofloxacin. Augmentin, doxycycline and chloramphenicol also showed high activities in the two serogroups while cotrimoxazole, tetracycline and amoxicillin exhibited the lowest activities (Table 5). Resistance of clinical isolates from Douala to these antibiotics has been reported by Garrigue et al. [37]. Such resistant strains might have been disseminated into water sources. Studies in other parts of the world $[38,39]$ have reported varying susceptibilities of the organism to these antibiotics. Changes in susceptibility pattern have been attributed to isolation time, source and geographical location. However, high activities of ofloxacin and ciprofloxacin observed in our study are similar to other studies $[15,38,39]$ and corroborate the use of fluoroquinolones as new alternatives for cholera treatment in some cholera endemic regions [40]. Our data and reports from other cholera endemic localities in Douala [20] therefore suggest ciprofloxacin and ofloxacin could be very good alternatives for chemotherapy during cholera or cholera-like disease outbreaks in Douala.

High resistance of $\mathrm{O} 1$ isolates to amoxicillin corroborates the report of Ngandjio et al. [20] on the emergence of resistance to amoxicillin toward the end of the 2005 cholera epidemic in Douala. Doxycycline and amoxicillin were extensively used during this outbreak as drugs of choice in chemotherapy and chemoprophylaxis [23,24]. Prolonged usage of antibiotics for curative and prophylactic purposes during an epidemic can provoke the emergence and spread of resistant strains into the environment [41]. Overuse of antibiotics could also exert a selective pressure on pathogenic organisms and the bowel flora, which once shed, become an important reservoir of resistance genes that can be transferred to other bacteria such as $V$. cholerae. Genetic exchange has been reported to occur between $V$. cholerae and enterobacteriaceae in the environment such as $E$. coli that possess transposon and plasmid of the same group [42].

Four multi-drug resistance (MDR) patterns emerged among $V$. cholerae $\mathrm{O} 1$ isolates (Table 6). Isolates that were resistant to more than 3 drugs were not found. The patterns $A M L^{\mathrm{R}} \mathrm{TE}^{\mathrm{R}} \mathrm{SXT}^{\mathrm{R}}$ and $\mathrm{TE}^{\mathrm{R}} \mathrm{SXT}^{\mathrm{R}}$ were the most common resistance patterns in this serogroup. Akoachere et al. [20] recently detected multi-drug resistant toxigenic $V$. cholerae O1 in Douala. Ndayo et al. [15] reported the isolation of MDR O1 strains from water sources in Douala that exhibited resistance to up to five drugs: $\mathrm{AML}^{\mathrm{R}} \mathrm{AUG}^{\mathrm{R}} \mathrm{TIC}^{\mathrm{R}} \mathrm{S}^{\mathrm{R}} \mathrm{C}^{\mathrm{R}} \mathrm{SXT}^{\mathrm{R}}$, a pattern similar to that obtained from clinical isolates during the 20042005 cholera epidemic. Like O1 isolates, multi-drug resistance was observed in the non-O1/non - O139 isolates. Thirteen MDR patterns were obtained (Table 6). Similar to serogroup O1, the pattern $\mathrm{AML}^{\mathrm{R}} \mathrm{TE}^{\mathrm{R}} \mathrm{SXT}^{\mathrm{R}}$ predominated. We also observed that most non-O1/non-O139 isolates were simultaneously resistant to cotrimoxazole and tetracycline. The isolation of $V$. cholerae that were resistant to cotrimoxazole suggests the possible presence of the SXT element in the study area. The SXT element is a selftransmissible, chromosomally integrated genetic element which carries cross-resistance to cotrimoxazole, streptomycin and furazoloidine [43]. However, we did not test streptomycin and furazoloidine in our study. The SXT element has been demonstrated to acquire additional tetracycline and erythromycin resistance genes with high efficiency [44]. Thus, tetracycline and cotrimoxazole resistance observed in isolates could be due to the SXT element. From our results and other findings in Douala $[15,20]$ it would be necessary to investigate drug resistant $V$. cholerae from Douala for these resistance markers. However, the simultaneous resistance to tetracycline and cotrimoxazole could be rather related to the presence of both SXT element and resistance (R) plasmid known to carry tetracycline resistance genes [45]. The high prevalence of MDR $V$. cholerae in the water sources indicates the need for constant monitoring of the susceptibility pattern of the organism in cholera-endemic areas, in anticipation of an outbreak of cholera or gastroenteritis. It is necessary that preparedness activities for chemotherapy should include an efficient scheme for the management of antibiotics chosen, as this influences the emergence and prevalence of novel antibiotic resistant clones in cholera endemic areas.

\section{Limitations}

We were not able to access all our sampling points during visits and this greatly affected our sample size. Analysis for 
toxin production or toxin production potential of isolates was not carried out. It is therefore difficult to associate these isolates with disease production particularly as they were all environmental isolates. We employed the disc diffusion technique to investigate the antibiotic susceptibility of isolates. MICs were not determined making it difficult to differentiate between strains that were very sensitive and those with higher MIC. This is important clinically because patients infected with strains whose MIC is high do not respond like those with very sensitive strains.

\section{Conclusions}

Our study has shown that V. cholerae is present all year round in wells and streams in Bepanda. Since wells are a major source of water in study area and the stream is used for various activities which may expose residents to infection, cholera will continue to be a health threat in this locality if intervention measures to prevent outbreak are not implemented. Among the intervention measures, this locality should be considered a target for oral cholera vaccine as an immediate measure while resources are put together for WASH (water, sanitation and hygiene) improvement.

\section{Additional files}

Additional file 1: Distribution of $V$. cholerae in contaminated water sources. This shows the distribution of Vibrio cholerae isolated from various sources in study area.

Additional file 2: Monthly isolation of Vibrio cholerae from various sources. This presents the monthly isolation of $V$. cholerae from each source. Additional file 3: Binary logistic regression analysis of physico-chemical parameters.

\section{Abbreviations}

CDC: Centre for disease control and prevention; WASH: Water, sanitation and hygiene.

\section{Competing interests}

The authors declare that they have no competing interests.

\section{Authors' contributions}

JTKA as principal investigator conceived, designed and coordinated the study, interpreted data and drafted the manuscript. KMCP analyzed samples and also participated in data interpretation. All authors read and approved the final manuscript.

\section{Acknowledgements}

We thank well and tap owners for authorizing us to collect water samples. We are grateful to Mr. Tanyimoh Nembualum for his assistance in statistical analysis. This work was carried out in the Laboratory for Emerging Infectious Diseases at the University of Buea and supported by the University of Buea Research Grant No. 2008/A6 awarded to Akoachere J-F.T.K

Received: 6 September 2013 Accepted: 11 July 2014 Published: 30 July 2014

\section{References}

1. Sack DA, Sack RB, Nair GB, Siddique AK: Cholera. Lancet 2004, 363(9404):223-233.

2. Morris JG Jr: Vibrio cholerae non-O1serogroup strains not associated with epidemic disease. In Vibrio cholerae and Molecular to Global Perspectives.
Edited by Wachsmuth Kl, Blake PA, Olsvik O. Washington, DC: American Society for Microbiology Press; 1994:103-115.

3. Crump JA, Bopp CA, Greene KD, Kubota KA, Middenforf RL, Wells JG, Mintz ED: Toxigenic Vibrio cholerae serogroup 0141-associated cholera-like diarrhea and blood stream infection in the United States. J Infect Dis 2003, 187:866-868.

4. Chakraborty S, Mukhopardhyay AK, Badhra RK, Ghosh AN, Mitra R, Shimada T, Yamasaki S, Faruque SM, Takeda Y, Colwell RR, Nair GB: Virulence genes in environmental strains of Vibrio cholerae. Appl Environ Microbiol 2000, 66:4022-4028

5. Li M, Shimada T, Morris JG Jr, Sulakvelidze A, Sozhamannan S: Evidence for the emergence of non-01 and non-0139 Vibrio cholerae strains with pathogenic potential by exchange of $\mathrm{O}$-antigen biosynthesis regions. Infect Immun 2002, 70(5):2441-2453.

6. Blokesh M, Schoolnik GK: Serogroup conversion of Vibrio cholerae in aquatic reservoirs. PloS Pathog 2007, 3(6):0477-0746.

7. Faruque SM, Albert AJ, Mekalanos JJ: Epidemiology, genetics, and ecology of toxigenic Vibrio cholerae. Microbiol Mol Biol Rev 1998, 68:1301-1314.

8. Colwell RR: Global climate and infectious disease: the cholera paradigm. Science 1996, 274:2025-2031.

9. Singleton FL, Attwell R, Jangi S, Colwell RR: Effects of temperature and salinity on Vibrio cholerae growth. Appl Environ Microbiol 1982, 44:1047-1058.

10. del Refugio MCC, Sedas VP, Borunda EO, Reynoso FL: Influence of water temperature and salinity on seasonal occurrences of Vibrio cholerae and enteric bacteria in oyster-producing areas of Veracruz México. Mar Pollut Bull 2005, 50(12):1641-1648.

11. Kumar PA, Patterson J, Karpagam P: Multiple antibiotic resistance profiles of Vibrio cholerae non-01 and non-0139. Jpn J Infect Dis 2009, 62(3):230-232.

12. Amaro C, Aznar R, Garay E, Alcaide E: R plasmids in environmental Vibrio cholerae non-O1 strains. Appl Environ Microbiol 1988, 54(11):2771-2776.

13. Guevart E, Noeske E, Solle J, Essomba JM, Ejeugaelé M, Bita A, Mouangue A, Manga B: Factors contributing to the endemcity of cholera in Douala Cameroon. Med Trop 2006, 66(3):283-291.

14. World Health Organization (WHO) Global Task Force on Cholera Control: Cholera Country Profile. Cameroon: 2012. www.who.int/cholera/countries/ CameroonCountryProfile2011.pdf.

15. Ndayo-Wouafo M, Noeske J, Pouillot R, Ngandjio A, Ejuigudé G, Quilici ML: Environmental determinants associated with V. cholerae in Douala, Cameroon. Rapport Scientifique Final Portant sur le Projet Intitulé; 2007. http://www. imea.fr/imea-fichiersjoints/imea-projets-soutenus/0506-Poster.pdf.

16. Akoachere J-FTK, Omam L-A, Masalla TN: Assessment of the relationship between bacteriological quality of dug-wells, hygiene behaviour and well characteristics in two cholera endemic localities in Douala, Cameroon. BMC Public Health 2013, 13:692.

17. Cameroon: Poor sanitation causes cholera outbreak in Douala. www.rinnews.org/ report/48721/cameroon-poor-sanitation-causes-cholera-outbreak-in-douala.

18. Cheesbrough M: Microbiological tests; Antimicrobial sensitivity testing; Water related diseases and testing of water supplies. In District Laboratory Practice in Tropical Countries Part II. Low Price Edition 2000th edition. Cambridge: Cambridge University Press; 2000:434.

19. Bag PK, Bhowmik P, Hadjra TK, Ramamuurthy T, Sakar P, Majunder M, Chwodhury G, Das MP: Putative virulence trait and pathogenicity of Vibrio cholerae non-01/non-0139 isolated from surface waters in Kolkata India. Appl Environ Microbiol 2008, 74(18):5635-5644.

20. Akoachere J-FTK, Masalla TN, Njom HA: Multi-drug resistant toxigenic Vibrio cholerae 01 is persistent in water sources in New Bell-Douala Cameroon. BMC Infect Dis 2013, 13:366.

21. Center for Disease Control and Prevention: Isolation and identification of Vibrio cholerae serogroup 01 and 0139. In Laboratory Methods for the Diagnosis of Epidemic Dysentery and Cholera. 1999:115.

22. National Committee for Clinical Laboratory Standards: Performance standard for antimicrobial disc susceptibility test: approved standards. 6th edition. Wayne PA: NCCLS document M2-A6; 2003.

23. Guévart E, Noeske J, Sollé J, Mouangue A, Bikoti JM: Large-scale selective antibiotic prophylaxis during the 2004 cholera outbreak in Douala (Cameroon). Sante 2007, 16(3):149-154.

24. Ngandjio A, Tejiokem M, Wouafo M, Ndome I, Yonga M, Guenole A, Lemee L, Quilici M-L. Fonkoua M-C: Antimicrobial resistance and molecular characterization of Vibrio cholerae 01 during the 2004 and 2005 outbreak of cholera in Cameroon. Foodborne Pathog Dis 2009, 6(1):49-56.

25. Cholera-Vibrio cholerae Infection: Antibiotic Treatment. www.cdc/cholera/ treatment/antibiotic-treatment.html. 
26. Colwell RR, Huq A: Environmental reservoir of Vibrio cholerae. The causative agent of cholera. Ann N Y Acad Sci 1994, 740:44-54.

27. Jesudason MV, Balaji V, Mukudan U, Thomas CJ: Ecological study of Vibrio cholerae in Vellore. Epidemiol Infect 2000, 124:201-206.

28. Dutta D, Chowdhury G, Pazhani PG, Guin S, Dutta S, Ghosh S, Rajendran K, Nandy RK, Mukhopadhyay AK, Bhattacharya MK, Mitra U, Takeda Y, Nair BG Ramamurthy T: Vibrio cholerae Non-01, Non-0139 Serogroups and Cholera-like Diarrhea, Kolkata. India. Emerg Infect Dis 2013, 19(3):464-467.

29. Farmachidi JP, Sobesky R, Bousougant Y, Quilici MZ, Coffin B: Septicemia and liver absesses secondary to non-01/non-0139 Vibrio cholerae colitis. Eur J Gastroenterol Hepatol 2003, 15:699-700.

30. Fernández JM, Serrano M, De Arriba JJ, Sánchez MV, Escribano E, Ferreras P: Bacteremic cellulitis caused by Non-01, Non-O139 Vibrio cholerae: report of a case in a patient with hemochromatosis. Diagn Microbiol Infect Dis 2000, 37(1):77-80

31. Colwell RR, Huq A, Chowdhury MA, Brayton PR, Xu B: Serogroup conversion of Vibrio cholerae. Can J Microbiol 1995, 41:946-950.

32. Ramamurthy T, Garg S, Sharmma R, Bhattarcharya SK, Nair GB, Shimada T, Takeda T, Karasawa T, Kurazano H, Pal A: Emergence of novel strain of Vibrio cholerae with epidemic potential in Southern and Eastern India. Lancet 1993, 341:703-704.

33. du Preez M, van der Merwe MR, Cumbana A, le Roux W: A survey of Vibrio cholerae 01 and 0139 in estuarine waters and sediments of Beira. Mozambique. Water SA 2010, 36(5):616-620.

34. Huq A, Colwell RR: Environmental factors associated with emergence of diseases with special reference to cholera. Eastern Mediterr Health $J$ 1996, 2(1):37-45.

35. Louis VR, Russek-Cohen E, Choopum N, Rivera ING, Gangle B, Jiang SC, Rubin A, Patz JA, Huq A, Colwell RR: Predicability of Vibrio cholerae in Chesapeake Bay. Appl Environ Microbiol 2003, 69:2773-2785.

36. Huq A, Sack RB, Nizam A, Longini IM, Nair GB, Ali A, Morris JG Jr, Khan MN, Siddique AK, Yunus M, Albert MJ, Sack DA, Colwell RR: Critical Factors influencing the occurrence of Vibrio cholerae in the environment of Bangladesh. Appl Environ Microbiol 2005, 71(8):4645-4654.

37. Garrigue GP, Ndayo M, Sicard JM, Fonkoua MC, Lemao G, Durand JP, Dodin A: Antibiotic resistance of strains of Vibrio cholerae El Tor isolated in Douala (Cameroon). Bull Soc Pathol Exot Filiales 1986, 79(3):305-312.

38. Campos LC, Zashner V, Avelar KES, Alvelar RM, Pereira DSG, Brazil JMV, Freitas FB, Salles CA, Karaolis DKR: Genetic diversity and antibiotic resistance of clinical and environmental Vibrio cholerae suggest that many serogroups are reservoirs of resistance. Epidemiol Infect 2004, 132(5):985-992.

39. Ibarra JO, Alvarado DE: Antimicrobial resistance of clinical and environmental strains of Vibrio cholerae isolated in Lima, Peru during epidemics in 1991 and 1998. Braz J Infect Dis 2007, 11(1):100-105.

40. Doganci L, Gun H, Baysallar M, Albay A, Cinar E, Asnedaroglu T: Short-term quinolones for successful eradication of resistant Vibrio cholerae in adult patients. Scand J Infect Dis 1995, 27:425-426.

41. Shears P: Recent development in cholera. Curr Opin Infect Dis 2001, 14:553-558.

42. Ogg L, Ryder R, Smith H: Isolation of Vibrio cholerae from aquatic birds in Colorado and Utah. Appl Environ Microbiol 1989, 55:95-99.

43. Waldor MK, Tschape H, Mekolanos JJ: A new type of conjugative transposon encodes resistance to sulfamethoxazole/trimethoprim and streptomycin in Vibrio cholerae 0139. J Bacteriol 1996, 178:4157-4165.

44. Faruque SM, Islam MJ, Ahmad QS, Biswas K, Faruque ASG, Nair GB, Sack RB, Sack DA, Mekalanos JJ: Improved technique for isolation of environmental Vibrio cholerae with epidemic potential: monitoring the emergence of a multiple antibiotic-resistant epidemic strain in Bangladesh. J Infect Dis 2006, 193:1029-1036.

45. Ceccarelli D, Salvia AM, Sami J, Cappuccinelli C, Colombo MM: New Cluster of Plasmid-Located Class 1 Integrons in Vibrio cholerae 01 and a dfrA15 Cassette-Containing Integron in Vibrio parahaemolyticus isolated in Angola. Antimicrob Agents Ch 2006, 50(7):2493-2499.

doi:10.1186/1471-2334-14-421

Cite this article as: Akoachere and Mbuntcha: Water sources as reservoirs of Vibrio cholerae $\mathrm{O} 1$ and non-O1 strains in Bepanda, Douala (Cameroon): relationship between isolation and physico-chemical factors. BMC Infectious Diseases 2014 14:421.

\section{Submit your next manuscript to BioMed Central and take full advantage of:}

- Convenient online submission

- Thorough peer review

- No space constraints or color figure charges

- Immediate publication on acceptance

- Inclusion in PubMed, CAS, Scopus and Google Scholar

- Research which is freely available for redistribution

Submit your manuscript at www.biomedcentral.com/submit 